\title{
Knowledge, attitude and practices regarding World Health Organization surgical safety checklist and the challenges in its implementation at a teaching hospital in North India
}

\author{
Priya Sharma, Vartika Tripathi*, Uma Gupta
}

Department of Obstetrics and Gynecology, Mayo Institute of Medical Sciences, Barabanki, Uttar Pradesh, India

Received: 29 June 2020

Accepted: 01 August 2020

*Correspondence:

Dr. Vartika Tripathi,

E-mail: vartikatripathi88@gmail.com

Copyright: () the author(s), publisher and licensee Medip Academy. This is an open-access article distributed under the terms of the Creative Commons Attribution Non-Commercial License, which permits unrestricted non-commercial use, distribution, and reproduction in any medium, provided the original work is properly cited.

\begin{abstract}
Background: The WHO in 2009 published the surgical safety checklist (SSC) for reducing the surgical complications. For its successful implementation it is imperative to identify the current knowledge, attitude and practices of the involved personnel and explore the anticipated barriers. Objective of this study was to evaluate the knowledge, attitude and practices of the participants about the SSC and determine the possible challenges in its implementation.

Methods: This study is a descriptive, cross-sectional study involving the use of a pre-tested questionnaire carried out in a teaching hospital. All personnel involved in the operation theater who gave their written consent were enrolled.

Results: Awareness regarding the SSC is high and existing practices are favorable towards patient safety amongst Hospital personnel. Attempts should be made to educate all personnel to gain complete knowledge regarding the checklist. The anticipated barriers, of which lack of knowledge was found to be the most prominent, should be dealt with.

Conclusions: A strategy aimed at proper education, stepwise implementation, alleviating the hindrances and regular feedbacks can result in decreasing the surgery related complications and morbidities through implementation of the surgical safety checklist.
\end{abstract}

Keywords: Implementation barriers, Patient safety, Surgical complications, Surgical safety checklist

\section{INTRODUCTION}

According to WHO there are approximately 234 million surgeries being performed annually worldwide. ${ }^{1}$ Surgical care is indispensable in saving lives and decreasing morbidities but it is also associated with a significant risk of complications and rarely even death. It is estimated that in developing countries there is a death rate of $5-10 \%$ for major surgeries and that about 7 million patients undergoing surgery land up in major complications, out of these 1 million died during or immediately after surgery annually. ${ }^{1}$ As per a systematic review performed in 2008 the majority of adverse events in a hospital were attributed to the operation theatre and $43 \%$ of these were preventable. ${ }^{2}$ In the recent years there has been increasing focus on these potentially preventable errors. A high functioning surgical team which follows a structured communication protocol is the cornerstone in achieving reduced rates of surgical complications. Based on this principal the World Health Organization (WHO) in 2009 published the surgical safety checklist (SSC) within its 'safe surgery saves lives' campaign. The SSC encompasses a simple set of surgical safety standards that can be used in any surgical setting. Each safety step on the checklist is simple, widely applicable, and measurable. The implementation of the SSC with the 
culture change associated with it brings about an environment of team work, cooperation and better communication leading to dramatic improvements in patient care.

In a cohort study conducted between October 2007 and September 2008 the effect of the checklist was studied in eight hospitals in eight cities worldwide. Data was prospectively collected on clinical processes and outcomes from 3733 patients before and 3955 patients after the Checklist was implemented. The results of the study published in the New England Journal of Medicine in January 2009 showed a $47 \%$ reduction in mortality and a $36 \%$ reduction in complications. ${ }^{3}$

There exist numerous difficulties in the execution and sustainable application of the SSC, more so in a developing nation like India. In 2012, Fourcade et al identified eleven organizational barriers to implementation of the checklist. ${ }^{4}$

For successful implementation of the SSC it is imperative to identify the current knowledge, attitude and practices of the involved personnel. It is also necessary to explore the barriers to its implementation so that apt strategies can be developed to overcome them.

\section{METHODS}

It is a descriptive, cross-sectional study which involved the use of a pre-tested questionnaire.

This study was carried out in a teaching hospital, over a period of 1 month (May 2020). Ethical clearance was obtained from the Institute's Ethics Committee. All personnel involved in the operation theater including the surgeons, interns, operation theater staff, peri operative nurses, anesthesiologist and nurse anesthetist were enrolled. All those who gave their written informed consent were recruited in the study and those who were not willing to participate were excluded.

\section{Questionnaire validation}

The questionnaire was designed in English language and was divided into 4 sections. The respondents were asked if they had heard of the SSC and their source of knowledge about the same. The knowledge of those who said yes was assessed using 6 questions which cut across the content, utilization, and application of the SSC. A scoring mechanism was used to understand overall knowledge level; a score of one was given for each correct response and zero for wrong response. Correctly answered questions were scored on a 6-point scale. This was further graded into good, average and poor knowledge. Poor knowledge was for correct responses between 1-2, average knowledge for a score of 3-4 while a score of 5-6 was labeled as having good knowledge. The part of the questionnaire testing the attitude of the personnel who were aware of the SSC, had 8 questions, and they had to be answered in terms of whether the participants strongly agreed, agreed, were neutral, disagreed or strongly disagreed with the provided statements. There were 8 questions for assessing the practice of the volunteers following the same format. They were also asked who according to them amongst the operation theater staff would be suitable for taking charge of the checklist. The last part of the questionnaire dealing with the challenges in the implementation of SSC had 13 choices and respondents could choose more than one option.

Pre-test of the questionnaires was carried out on 5 surgeons and corrections made accordingly. All information obtained from this study has been kept confidential and will not be linked to the participants in anyway.

\section{Statistical analysis}

Data was statistically analyzed using Microsoft excel.

\section{RESULTS}

The survey was administered to 122 personnel and 104 of them responded to it (85.52\% response rate): 36 surgeons (34.61\% of all respondents) including department of surgery, orthopaedics, ear, nose and throat surgeon, ophthalmology, obstetrics and gynecology. Six anaesthesiologists $(5.76 \%), 12$ operation theatre staff and nurses $(11.53 \%)$ and 50 interns $(48.07 \%)$ posted in the various surgical departments. There were $39(37.5 \%)$ females and $65(62.5 \%)$ males. The mean age of the study population was $30.1 \pm 7.34$. The youngest person being 23 years old while the oldest being 62 years old.

Of 104 personnel, majority $96(92.3 \%)$ had heard of the SSC, whereas $8(7.69 \%)$ were unaware of it. The most common source of information was found to be the internet $(n=41)$ and books $(n=29)$ followed by training courses $(n=26)$. Publicity at the hospital $(n=15)$ and colleagues $(n=13)$ as mediums of information were chosen by fewer respondents. Knowledge of the personnel which was assessed using a 6-point scale showed that maximum number of volunteers $52(54.17 \%)$ had good knowledge regarding SSC, 35 (36.83\%) had average while $9(9.3 \%)$ had poor knowledge about SSC.

Table 1 shows the current perception and practices of the respondents with respect to safety culture, communication and team work in the operation theatre.

The attitude of the personnel, who were aware of the SSC, has been summarized in Table 2 .

Out of 104 people enrolled in the study, 36 (37.5\%) felt that a dedicated staff for the sole purpose of taking charge of the checklist would be apt. Anaesthesiologists were chosen by $18(18.75 \%)$ for taking charge of the SSC. Fifteen $(15.26 \%)$ people felt that all operating room staff 
should take charge of the SSC and 15 (15.26\%) said that it should be given to the operating surgeon. Whereas 11 $(11.46 \%)$ volunteers wanted the nursing staff to head the checklist and one person felt that whoever is present as per convenience could take charge. The challenges that might affect the implementation of the checklist in decreasing order of frequency have been mentioned in Table 3.

Table 1: The current perception and practices of the respondents with respect to safety culture, communication and team work in the operation theatre.

\begin{tabular}{|c|c|c|c|c|c|c|}
\hline Opinion & $\begin{array}{l}\text { Strongly } \\
\text { agree } \\
\mathbf{N}(\%)\end{array}$ & $\begin{array}{l}\text { Agree } \\
\mathbf{N}(\%)\end{array}$ & $\begin{array}{l}\text { Neutral } \\
\mathbf{N}(\%)\end{array}$ & $\begin{array}{l}\text { Disagree } \\
\mathbf{N}(\%)\end{array}$ & $\begin{array}{l}\text { Strongly } \\
\text { disagree } \\
\mathbf{N}(\%)\end{array}$ & $\begin{array}{l}\text { Total } \\
\mathrm{N}=104\end{array}$ \\
\hline $\begin{array}{l}\text { There is widespread adherence to } \\
\text { rules and clinical guidelines in our } \\
\text { operating room }\end{array}$ & $15(14.42)$ & $51(49.03)$ & 17 (16.34) & $19(18.26)$ & $2(1.92)$ & 104 \\
\hline $\begin{array}{l}\text { Patient safety is the responsibility } \\
\text { of all operating room staff }\end{array}$ & $62(59.61)$ & $42(40.38)$ & $0(0.0)$ & $0(0.0)$ & $0(0.0)$ & 104 \\
\hline $\begin{array}{l}\text { Patient safety is a high priority in } \\
\text { our operating rooms }\end{array}$ & $49(47.11)$ & $51(49.03)$ & $4(3.84)$ & $0(0.0)$ & $0(0.0)$ & 104 \\
\hline $\begin{array}{l}\text { In our unit, we all know our staff } \\
\text { members by first and last name }\end{array}$ & $32(30.76)$ & $48(46.15)$ & $11(10.57)$ & $13(12.50)$ & $0(0.0)$ & 104 \\
\hline $\begin{array}{l}\text { There is enough time for safety } \\
\text { preparation in our operating room }\end{array}$ & $17(16.34)$ & $62(59.61)$ & $11(10.57)$ & $6(5.77)$ & $8(7.69)$ & 104 \\
\hline $\begin{array}{l}\text { Information and suggestions are } \\
\text { heard readily }\end{array}$ & $31(29.80)$ & $37(35.57)$ & 19 (18.26) & $15(14.42)$ & $2(1.92)$ & 104 \\
\hline $\begin{array}{l}\text { Team in the OT has good } \\
\text { coordination }\end{array}$ & $18(17.30)$ & $58(55.76)$ & $15(14.42)$ & $2(1.92)$ & $11(10.57)$ & 104 \\
\hline $\begin{array}{l}\text { Resources and enough to ensure } \\
\text { safety }\end{array}$ & $13(12.05)$ & $46(44.23)$ & $26(25.00)$ & $15(14.42)$ & $4(3.84)$ & 104 \\
\hline
\end{tabular}

Table 2: The attitude of the personnel who were aware of the SSC.

\begin{tabular}{|c|c|c|c|c|c|c|}
\hline Opinion & $\begin{array}{l}\text { Strongly } \\
\text { agree } \\
\mathbf{N}(\%)\end{array}$ & $\begin{array}{l}\text { Agree } \\
\mathbf{N}(\%)\end{array}$ & $\begin{array}{l}\text { Neutral } \\
\mathbf{N}(\%)\end{array}$ & $\begin{array}{l}\text { Disagree } \\
\mathbf{N}(\%)\end{array}$ & $\begin{array}{l}\text { Strongly } \\
\text { disagree } \\
\mathbf{N}(\%)\end{array}$ & $\begin{array}{l}\text { Total } \\
\mathrm{N}=96\end{array}$ \\
\hline $\begin{array}{l}\text { I want the checklist to be used } \\
\text { for all this study surgical } \\
\text { procedures }\end{array}$ & $60(62.50)$ & $28(29.17)$ & $8(8.33)$ & $0(0.0)$ & $0(0.0)$ & 96 \\
\hline $\begin{array}{l}\text { The checklist seems like an } \\
\text { unnecessary tick-box }\end{array}$ & $0(0.0)$ & $0(0.0)$ & $14(14.58)$ & $46(47.91)$ & $36(37.5)$ & 96 \\
\hline $\begin{array}{l}\text { We can operate efficiently without } \\
\text { having to use this checklist }\end{array}$ & $0(0.0)$ & $18(18.75)$ & $22(22.91)$ & $42(43.75)$ & $14(14.58)$ & 96 \\
\hline $\begin{array}{l}\text { The checklist might waste time } \\
\text { and can make our operating } \\
\text { theatres less efficient }\end{array}$ & $0(0.0)$ & $16(16.66)$ & $2(2.08)$ & $48(50.00)$ & $30(31.25)$ & 96 \\
\hline $\begin{array}{l}\text { Surgical safety checklist causes } \\
\text { irritation between staff members }\end{array}$ & $0(0.0)$ & $12(12.50)$ & $17(17.70)$ & $55(57.29)$ & $12(12.50)$ & 96 \\
\hline $\begin{array}{l}\text { The checklist will improve } \\
\text { communication and collaboration } \\
\text { between staff in the operating } \\
\text { room }\end{array}$ & $24(25.00)$ & $54(56.25)$ & $14(14.58)$ & $0(0.0)$ & $4(4.16)$ & 96 \\
\hline $\begin{array}{l}\text { The checklist may not bring any } \\
\text { extra value to existing safety } \\
\text { procedures already in place in the } \\
\text { theatre before its implementation }\end{array}$ & $2(2.08)$ & $23(23.96)$ & $16(16.66)$ & $33(34.37)$ & $22(22.91)$ & 96 \\
\hline The checklist is easy to use & $17(17.70)$ & $59(61.45)$ & $16(16.66)$ & $4(4.16)$ & $0(0.0)$ & 96 \\
\hline
\end{tabular}


Table 3: Challenges that might affect the implementation of the checklist in decreasing order of frequency (includes multiple responses).

\begin{tabular}{|l|l|}
\hline Challenges & Frequency \\
\hline Lack of awareness or knowledge & 16 \\
\hline Shortage/lack of manpower & 14 \\
\hline Lack of good communication & 13 \\
\hline Commitment of staff to duty & 12 \\
\hline Lack of commitment from the management & 12 \\
\hline Co-operation among staff & 11 \\
\hline Inadequate supply of consumable instruments/other equipment/facilities & 11 \\
\hline Lack of interest/will/attitude of health worker & 11 \\
\hline Lack of team spirit & 11 \\
\hline Lack of incentive among theatre workers & 10 \\
\hline Administrative bottleneck/bureaucracy & 10 \\
\hline Inadequate time to carry out the checklist & 8 \\
\hline Corruption & 7 \\
\hline
\end{tabular}

\section{DISCUSSION}

As per this study majority of personnel were aware of the SSC and more than half had good knowledge regarding the same. The candidates were well aware of the objectives, components and implementation protocols of the SSC. These findings were similar to a previous study done in 2012 by Hurtado et al in Guatemala and Dangyangs et al who conducted a study on SSC in a hospital in Nigeria in 2016..$^{5,6}$ Although high level of knowledge regarding the checklist is encouraging, all attempts should be made to achieve universal awareness in terms of the purposes and components of the SSC.

The most common source of information was found to be the internet while the hospital was the source of knowledge for a relatively few personnel reflecting the need for more comprehensive hospital-based learning initiatives. Amongst the respondents maximum people agreed that there is widespread adherence to rules and clinical guidelines with patient safety being the highest priority and everyone's responsibility in the operation theater. The current practices in the hospital reflect the staff's readiness to adapt to new rules and their willingness to adhere with the regulations that ensure better patient care.

Team work and good communication are one of the most important pillars over which the SSC functions. Three fourth of the participants claimed to know all the members of the operating team on the first and last name basis and about the same proportion of respondents agreed to having good team coordination in the operation theater. Moreover, two third of the participants felt that team members were receptive to their suggestions and ideas. Growing evidence suggests that teamwork in surgery leads to improved outcomes and significantly reduced rates of adverse events. ${ }^{7,8}$ The effective integration of SSC into the system can only be ensured by a team that is both well-coordinated and well communicated. Whereas, the adaptation of the checklist itself cultivates an atmosphere of team work in the theater. However, one fourth of the staff members felt that the time they had for preparation in the operation theater was not enough and approximately half of them also disagreed to having enough resources in the theater to ensure patient safety. Similar findings were reported by Dangyangs et al who also pointed out that the rectification of these loopholes can go a long way in improving the work culture in any hospital. ${ }^{6}$

The overall attitude of the participants towards the checklist was favorable. Most of the members wanted the checklist to be used for all surgical procedures and anticipated that its use would improve communication and collaboration between staff in the operating room. Only about one fifth of the personnel believed that they can operate efficiently without the checklist, it runs the risk of causing irritation between the staff, the process seems time consuming and consequently it might not bring any added benefit to the existing safety culture. Majority of the participants said that the checklist is easy to use and is not just an unnecessary tick-box. Similarly, an online global survey done on frontline medical professionals by Vohraa et al showed the positive attitude of the professionals towards the checklist. ${ }^{9}$ Cullati et al in 2014 reported that both surgeons and anesthetists at the $97^{\text {th }}$ Annual Meeting of the Swiss Society of Surgery, Switzerland in 2010. perceived the SSC as a valuable tool in improving intra operative patient safety and communication among health care professionals, with lesser importance in facilitating teamwork. ${ }^{10}$ In the current study a dedicated staff for the taking charge of the checklist was suggested by one third of the personnel contrary to the study by Dangyangs et al where nurses were thought to be the apt personnel to take charge. ${ }^{6}$ 
Despite the initiative taken by WHO to advertise and adopt the checklist especially in low income countries where its benefits are obvious, there are certain sociocultural and organizational hurdles that need to be addressed to improve outcomes. The most common barrier to the SSC was listed to be the lack of knowledge, which can be easily ameliorated by awareness programmers, in situ demonstrations, videos and doubt clearing sessions organized by the hospital. This should be obtained through focused training in the area with all items being introduced in a stepwise manner. Besides teaching modules, posters, newsletters or computer screen savers can also be used as platforms for dissemination of information.

Lack of manpower and resources was also identified to be a grave challenge in the implementation of the SSC. Without the enough supply of resources and adequate manpower the adaptation of a commitment dependent strategy like SSC is impossible. Lack of communication between the operating team members acts as a hindrance to the smooth functioning of the SSC. This has also been suggested by Forcade et al who found out that poor communication between anesthetist and surgeon is the second most common cause of failure of the implementation of the checklist. ${ }^{4}$ For there to be a lasting cultural change in the operation theater working, the team members should themselves take initiatives rather than relying on the pressure from the management. This study was carried out in a private medical college, a multicentric study involving Government Hospitals and other private sectors would be more productive and go a long way in ensuring the use of SSC.

\section{CONCLUSION}

The WHO surgical safety checklist is a robust and simple tool to increase patient safety especially in low- and moderate-income countries. There is a high level of awareness regarding the SSC amongst staff at the Hospital. However, attempts should be made to educate all personnel to gain complete knowledge regarding the checklist. The practices and perception of respondents at the study hospital towards patient safety culture, communication and team work was found to be favourable. The participants also displayed enthusiasm and readiness to adapt the SSC in routine functioning of the operation theatre. The willingness of the staff members should be encouraged by dealing with the anticipated barriers, of which lack of knowledge was found to be the most prominent. A strategy aimed at proper education, stepwise implementation, alleviating the hindrances and regular feedbacks can result in decreasing the surgery related complications and morbidities through implementation of the surgical safety checklist.

Funding: No funding sources

Conflict of interest: None declared

Ethical approval: The study was approved by the Institutional Ethics Committee

\section{REFERENCES}

1. Weiser TG, Regenbogen SE, Thompson KD, Haynes AB, Lipsitz SR, Berry WR, et al. An estimation of the global volume of surgery: a modelling strategy based on available data. Lancet. 2008;372(9633):139-44.

2. De Vries EN, Ramrattan MA, Smorenburg SM, Gouma DJ, Boermeester MA. The incidence and nature of inhospital adverse events: a systematic review. Qual Saf Health Care. 2008;17:216-23.

3. Haynes AB, Weiser TG, Berry WR, Lipsitz SR, Breizat $\mathrm{AH}$, Dellinger EP, et al. A surgical safety checklist to reduce morbidity and mortality in a global population safe surgery saves lives study group. $\mathrm{N}$ Engl $\mathrm{J}$ Med. 2009;360(5):491-9.

4. Fourcade A, Blache JL, Grenier C, Bourgain JL, Minvielle E. Barriers to staff adoption of a surgical safety checklist. BMJ Qual Saf. 2012;21:191-7.

5. Hurtado JJ, Jiménez X, Peñalonzo MA, Villatoro C, de Izquierdo S, Cifuentes $\mathrm{M}$. Acceptance of the WHO surgical safety checklist among surgical personnel in hospitals in Guatemala City. BMC Health Serv Res. 2012;12(1):169.

6. Dangyangs SY, Afonne C. Awareness, knowledge and perception of safe surgery checklist and its implementation in jos university teaching hospital, Plateau State, Nigeria South American Journal of Clinical Research Special Edition 2016:1. Available at: https://www.academia.edu/31424560/Awareness

_Knowledge_and_Perception_of_Safe_Surgery_Checklist _and_its_Implementation_in_Jos_University_Teaching_H ospital_Plateau_State_Nigeria. Accessed on $08^{\text {th }}$ May 2020.

7. Mazzocco K, Petitti DB, Fong KT, Bonacum D, Brookey J, Graham S, et al. Surgical team behaviors and patient outcomes. The American Journal of Surgery. 2009 May 1;197(5):678-85.

8. Lingard L, Regehr G, Orser B, et al. Evaluation of a preoperative checklist and team briefing among surgeons, nurses, and anesthesiologists to reduce failures in communication. Arch Surg. 2008;143:12-8.

9. Vohraa RS, Cowleyb JB, Bhasinc N, Barakatd HM, Goughe MJ. On behalf of the Schoolofsurgery.org, Attitudes towards the surgical safety checklist and factors associated with its use: a global survey of frontline medical professionals. Annal Med Surg. 2015;4:119e123.

10. Cullati S, Licker MJ, Francis P, Degiorgi A, Bezzola P, Courvoisier DS, et al. Implementation of the surgical safety checklist in switzerland and perceptions of its benefits: cross-sectional survey. PLoS ONE. 2014;9(7):e101915.

Cite this article as: Sharma P, Tripathi V, Gupta U. Knowledge, attitude and practices regarding world health organization surgical safety checklist and the challenges in its implementation at a teaching hospital in North India. Int J Reprod Contracept Obstet Gynecol 2020;9:3759-63. 